\title{
Stress, Health and Happiness of Students
}

${ }^{1}$ Dr. Nitin Vighne, ${ }^{2}$ Ms. Pallavi Waghmare

${ }^{1}$ Ph.D. Student, Clinical Psychologist \& Career Counselor

${ }^{2}$ Student, Shri Ramdeobaba College of Engineering and Management, Nagpur

Email:nitinvighne@gmail.com,waghmarepv@rknec.edu

\section{Received: $20^{\text {th }}$ September 2018, Accepted: $11^{\text {th }}$ October 2018, Published: $31^{\text {st }}$ October 2018}

\begin{abstract}
Genuine Learning is always a pleasant experience, but 24 students commit suicide every day because of educational stress. Thus, stress poses as a significant public health problem, especially in India, for many students due to the highly competitive examination system and the school environment producing various other academic, social, and personal challenges therefore impacting their overall perceived happiness. The primary purpose of this research was to find out why students are not happy in current times \& how and what should be done to make education process a happy and stress free experience for students and teachers. The study examines whether students' perceived happiness differed significantly based on stress and emotional closeness to others, like teachers and parents (social support) and to explore the ways to maintain and improve their Happiness Quotient (HQ). For this, the authors have adopted a qualitative approach and collected data through a semi-structured interview design from students, teachers and student counselors. This research revealed that if we are able to eliminate root causes for educational stress on young minds after exploring the psychological requisites for happiness and implement them; then we can expect our students to achieve success in various fields and prevent suicides. Potential methods for combating the challenges of academic stress are then suggested to help shape a healthy, safe and friendly environment for all who live, learn and work in school that support their social and emotional well-being.
\end{abstract}

\section{Keywords}

Educational Stress, Happiness, Happiness Quotient, Emotional Support

\section{Introduction}

As per the state government record, in the last five years a total of 39,775 students killed themselves. The average comes to one student's suicide every hour in Maharashtra. Many students live a miserable life far, far away from the state of happiness. In classrooms, teachers become concentrated on covering the syllabus, often ignoring the grasping level of students (Raina, 1983). Partly because school success has such an important role in determining a child's future, it has come to be a critical measure of self-worth for young Indians; thus students and parents place major importance on the adolescents' academic work (Varma, 1998). Ultimately, problems like school drop-outs, suicides, crimes, and diseased patients are originated from unhappiness generated from environment, experience, education, unfulfilled needs and various other reasons. Psychiatrists have expressed concern at the emergence of education as a serious source of stress for school-going children, leading to an incidence of suicide deaths (D'Mello, 1997). With reference to the subject of this paper we are focusing on prerequisites for happiness which can be generated through the system of education.So the questions that arise are

\section{What is really happiness? How can we always stay happy? \\ Can we measure Quality and Quantity of Happiness, in order to stay happy always? \\ What are the basic psychological requisites in the education process to generate happy minds?}

These questions are discussed globally for improving happiness of all. There are researches done at the international level to determining the happiest and the saddest countries of the world, judged by Happiness Index of the people. India ranked 122 out of total 155 participant countries in the year 2017, which is clearly a quite low rank. However our rank came further down to 133 in the year 2018. This rank is calculated by using the following six parameters:
1. GDP per capita
2. Social support
3. Health life expectancy at birth
4. Freedom to make life choices
5. Generosity
6. Perceptions of corruption

However, these parameters are not accepted as accurate and reliable means in all the countries to find out the Happiness Index of people. 
In recent years, the subject of positive psychology has surfaced to bring knowledge to the role of psychology in making life more satisfying, boosting human functioning, and increasing overall happiness (Seligman 2002).Present day Psychologists regularly allude to happiness as Positive Affect - a mood or emotional state which is brought about by generally positive thoughts and feelings. Positive affect recognizes with low dispositions and antagonism, a perspective portrayed as Negative Affect in which individuals take a cynical perspective of their accomplishments, life circumstance and future prospects. Watson and Tellegen (1985) concluded that positive (e.g., happiness) and negative (e.g., stress) affects were two orthogonal dimensions, which suggests that it is possible to feel both emotions simultaneously. When we talk about happiness, we are referring to a person's pleasure or satisfaction, which may last only a couple of minutes or stretch out over the period of a lifetime. Happiness does not have to be expressed in order to be enjoyed - it is an internalized experience, varying in degrees, from eternal happiness experienced in serene "Samadhi" in Ashtanga Yoga, mild satisfaction in day to day life, to wild euphoria. Happiness is also expressed in other words as a sense of well-being, quality of life, flourishing, pleasure, and contentment. However, most religions and scholars of Asian origin, including India and China, believe that ultimate happiness is only achieved by overcoming craving for anything. Happiness is not solely derived from external, momentary pleasures. Indeed, despite the popular notion that happiness is fleeting, studies suggest that happiness is actually rather stable over time.

Happiness quotient is a basic conception that estimates the degree or amount of happiness and joys a person experiences. Fourteen areas within core questions for calculating happiness quotient of a person include: (1)business \& financial, (2) person engagement, (3) communications \& technology, (4) diversity (social issues), (5) education \& families, (6) emotions and feelings (well-being), (7) environment \& energy, (8) nourishment \& shelter, (9) government and politics, (10) law \& order (safety), (11) health and well-being, (12) religion and morals, (13) transportation, and (14) work.

\section{Happiness Generation Theories (HQ: Happiness Quotient)}

Ashtanga Yoga:

Ashtanga Yoga is more than 10,000 years old and according to it, the happiness concept talks about liberation from materialistic and temporary benefits to eternal joy by uniting physical body with the Atma (soul or spirit) of a person and then uniting further with Parmatma (God). In this eight-stage process, one gets physically and psychologically strong as a result of practicing and balancing needs by power of restrain and total control and finally achieving Superlative Consciousness and Eternal Bliss. Yoga, as a way of life, is a very effective way of enhancing one's HQ.

Maslow's Hierarchy of Needs:

Maslow's hierarchy of needs is a pyramid delineating the levels of human needs, mental, and physical. At the point when an individual ascends the steps of the pyramid, he achieves self-completion. Beyond the routine of necessities satisfaction, Maslow imagined moments of phenomenal experience, known as pinnacle encounters, significant snapshots of affection, comprehension, joy, or happiness, amid which a man feels all the more entire, alive, independent, but then a piece of the world. This is like the Flow Concept of Mihály Csíkszentmihályi.

Self-Determination Theory:

Self-determination theory relates intrinsic motivation of a person to three needs: competence, autonomy, and relatedness.

Positive Psychology:

This concept has produced many different views on causes of happiness, and on factors that correlate with happiness. Numerous short-term self-help interventions have been developed and demonstrated to improve wellbeing. Seligman's acronym PERMA summarizes five factors correlated with well-being:

1. Pleasure (delicious food, hot showers, and so forth),

2. Engagement (or flow, the assimilation of an enjoyed yet difficult movement),

3. Relationships (social relations have turned out to be extremely reliable marker of happiness),

4. Meaning (a perceived mission or belonging to something bigger), and

5. Accomplishments (having realized actual goals).

Observations from Influencing Factors and Time Tested Doctrines in Psychology.

Scientifically, Happiness is a Result or output of six major inputs. Repeated regular pattern of ABC leads to D i.e. Destiny or Future. Any positive emotion like Love, Faith, and Happiness is a result of basic inputs provided through six Es described in a text box below 
Generation Process of Thoughts \& Emotions

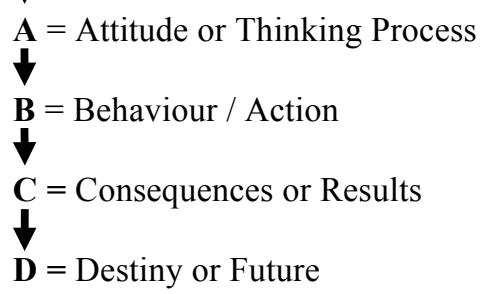

For example, if a teacher is lacking in KSA i.e. knowledge $(\mathrm{K})$, communication skills $(\mathrm{S})$ or Passion for his/her subject (Attitude=A); then students may begin to dislike that subject. Or if teacher is not attached or devoted to his subject or students, then, in turn, students also will not have any attachment with that specific subject and even with that teacher. Similarly, negative emotions like Fear, Anger etc. are also generated through exactly the same process explained above and shown in Figure 1 below.

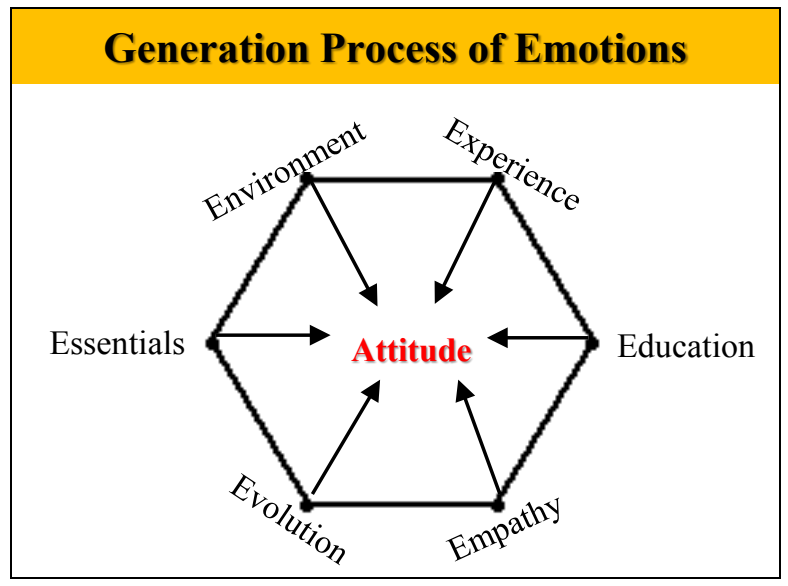

Figure 1: Six Major Inputs of Happiness

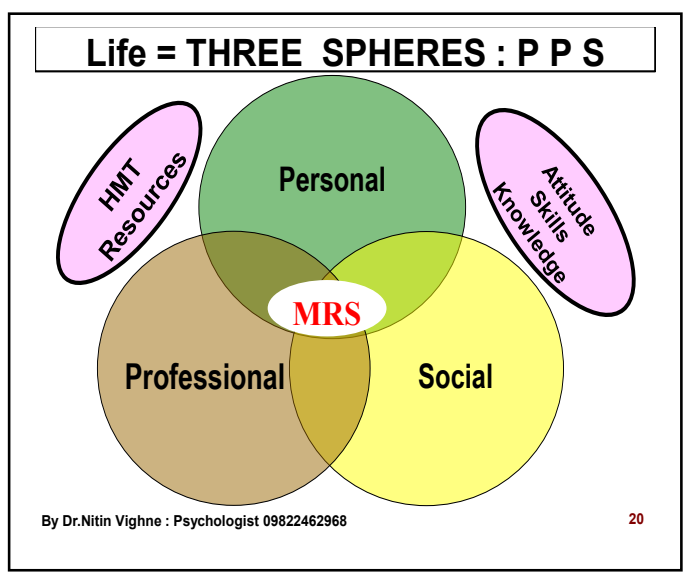

Figure 2: Three Spheres of Life

Figure 2 explains that all of us have three spheres of life-Personal, Professional and Social (PPS). Using our basic resources like Human, Material (Money), and Time, through these three Spheres PPS, we try to get MRS i.e. Money, Respect and Satisfaction (shown in the very centre as MRS). To earn MRS we have to develop the right kind of strengths or KSAs i.e. Knowledge, Skills and Attitude, but in this process we are influenced by six factors, right from our birth to the present day of our lives. These six influencing factors are nothing but the six Es discussed before (Environment, Experience, Education, Empathy, Evolution and Essentials).

\section{Science Behind Generation of Happiness:}

The Three Happy Messengers: It is found out that three neurotransmitters- Serotonin, Nor-epinephrine and Dopamine are responsible to create happiness. Hence they are also known as Happy Messengers of the brain. These 3 major hormones create happy feelings in humans, also displayed in the figure below.

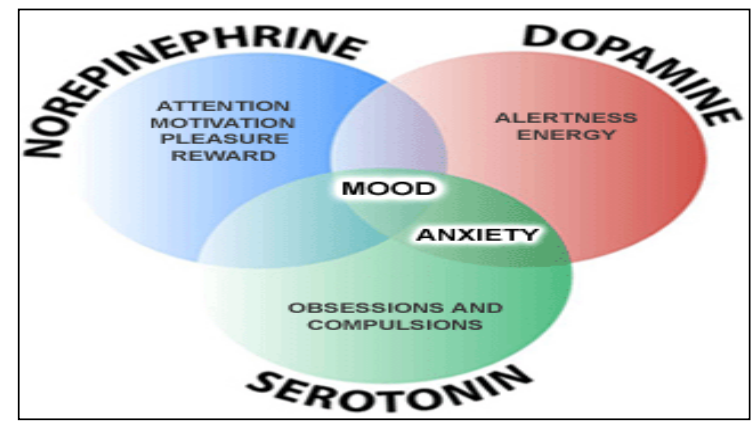

Figure 3: Hormones Responsible For Creating Happiness

Some other key hormones that create happy feelings are (many of the ones below also act as neurotransmitters): 
1. ACETYlCHOLINE: Alertness, Memory, Sexual Performance, Appetite Control, Release of Growth Hormone.

2. DOPAMINE: Feelings Of Bliss \& Pleasure, Euphoric, Appetite Control, Controlled Motor Movements, Feel Focused.

3. ENDORPHINS: Mood Elevating, Enhancing, Euphoric. The More Present, The Happier You Are! Natural Pain Killers.

4. ENKEPHALINS: Restrict Transmission Of Pain, Reduce Craving, And Reduce Depression.

5. GABA (Gamma Amino Butyric Acid): Found Throughout Central Nervous System, Anti-stress, Antianxiety, Anti-panic, Anti-pain; Feel Calm, Maintain Control, Focus.

6. MELATONIN: "Rest and Recuperation" And "Anti-aging” Hormone. Regulates Body Clock.

7. NOREPINEPHRINE: Excitatory, Feel Happy, Alert, Motivated. Anti-depressant, Appetite Control, Energy, Sexual Arousal.

8. OXYTOCIN: Stimulated By Dopamine. Promotes Sexual Arousal, Feelings Of Emotional Attachment, And Desire To Cuddle.

9. PHENYLETHYLMINE (PEA): Feelings of Bliss, Involved In Feelings of Infatuation (High Levels Found In Chocolate).

10. SEROTONIN: Promotes \& Improves Sleep, Improves Self Esteem, Relieves Depression, Diminishes Craving, Prevents Agitated Depression And Worrying.

\section{Materials and Methods}

Keeping in mind the objectives of the research with respect to the well-being of students and teachers, the following Research Hypothesis has been comprehended.

Research hypothesis: The systematized tools and techniques, if properly applied can reduce stress levels effectively and can make education a very pleasing, rewarding and satisfying experience to generate health and happiness among students and teachers.

Primary data, which was qualitative in nature, was collected from the respondents by conducting interviews. Students, Teachers and Student-Counselors were also made to fill a detailed questionnaire which had a semistructured design comprising of questions based on their interests, preferences and other likings. Students, their Teachers and Counselors were randomly selected from CBSE \& State Board Schools of Nagpur city. A total of 85 Students, 10 Teachers and 5 Counselors responded through the questionnaire. Different set of questions were designed and asked to the students, teachers and the counselors so as to know and understand their psychological requisites for happiness.

A) THE STUDENTS: Students studying in standard $8^{\text {th }}$ and $9^{\text {th }}$ filled the questionnaire. Through 25 questions, data was collected from the students, mainly concerning the statistics of subject coverage \& attendance, student's family, academic and social background; student's awareness about teacher's punctuality, dress \& appearance, attitude, knowledge and skills etc. were asked. School and Family environment was researched to find out student's happiness quotient. Other questions were student's order of liking or fondness for their subjects and teachers with respect to their academic performance.

B) Teachers: Through 24 questions \& parameters, information was collected from teachers regarding various aspects related to their jobs. Questions on statistics of subject coverage \& attendance, teacher's professional background, teacher's attitude, knowledge and skills etc. were a part of the questionnaire. Teacher's passion for the subject \& student's performance were asked as well. Teacher's self-appraisal was also taken based on 15 parameters including SWOT analysis and job satisfaction level.

C) Student-Counselors / Psychologists: Considering their job profile, a total of 10 questions were asked to the counselors related to their self-appraisal (based on 15 parameters including SWOT analysis), their level of job satisfaction. They were also questioned about the systems, tools and techniques adopted by them to ensure a healthy learning environment in schools. Other questions inquired about the number of classes / counseling sessions conducted by them in a day, interaction with parents and bonding with students.

\section{Results and Discussion}

After collection of data was completed, it was analyzed and interpreted separately for the students, teachers and student-counselors. Various questions related to the teachers' skills and abilities were answered by the students. Unfortunately, the results turned out to be quite negative on the part of the teachers as students feel that $80 \%$ teachers have poor class control and are always under some or the other kind of stress. Students also felt that $90 \%$ teachers have poor teaching skills including poor power of expression, language and reported that they were unable to create a happy class environment for learning. $80 \%$ teachers were testified to have poor subject command and knowledge which affected their academic performance. A notable observation from the data was that according to the students, $100 \%$ or all teachers looked well-dressed and presentable in school. $90 \%$ students feel their teachers have lot of scope to improve in teaching skills, subject knowledge $\&$ attitude area. They have 
many problems in conceptual clarity but teachers are not well equipped to do justice as per student's requirements.

According to the data teachers have the following opinions about their skills and abilities. $70 \%$ Teachers have average confidence level about their subject knowledge, While $10 \%$ reported to have very poor knowledge due to poor interest in the subject.70 \% Teachers agreed to have average teaching skills and felt they weren't as resourceful and creative in their teaching. $95 \%$ Teachers felt that they have good class control but students are not good and get distracted easily. $90 \%$ Teachers are poorly aware about their own SWOT analysis but feel that they are good teachers. Also, $92 \%$ Teachers know poorly of their students' SWOT analysis \& have very less bonding with them. $97 \%$ Teachers conveyed that they have very poor job satisfaction for various reasons. $75 \%$ Teachers have poor job commitment and most of them are victims of hectic routines and need regular training and counseling support. Teachers themselves are not happy with their job. They are not equipped with awareness and knowledge to create happiness in the minds of students.

Analysis of data collected from counselors reflected the following facts. $90 \%$ counselors have limited work experience but workable problem solving skills. $98 \%$ counselors enjoy good bonding and counseling skills with students but feel demand is higher than time available to them. $90 \%$ feel they have good power of SWOT analysis of self \& students. $90 \%$ counselors confessed poor job satisfaction due to poor utilization of their time by management for desired job profile. Most of them feel they are misused for other tasks than their actual professional function. $98 \%$ counselors are unhappy due to poor learning environment, distractions and poor job satisfaction.

Hypothesis Testing : The Hypothesis "The systematized tools and techniques if properly applied can reduce stress levels effectively and can make education a very pleasing, rewarding and satisfying experience to generate health and happiness among students and teachers. " is tested positive.

\section{Conclusion}

After deeply analyzing various observations generated from interviews \& questionnaire from students, teachers, student-counselors the following conclusions are made. To improve the overall happiness quotient of students in education following requisites are to be fulfilled:

1. Teachers must be aware about the student's environments and problems and try to improve their knowledge, skills and attitude. Teachers must understand the Science of Happiness. Only happy teachers can generate happy students. Balance of nutrients-exercise-rest \& positive attitude training can ensure learning happiness.

2. School / College Administration must organize student's and Parent's Training Programs by Psychologists during PTA meetings / or in college hours.

3. Organization should make optimum and right use of counselor than giving them other irrelevant duties. In absence of Counselors, organization should form a tie-up with Psychologists to ensure the same.

\section{References}

[1] Raina, M.K., 1983. Biochemical consequences of examination stress. Indian Educational Review, 18(2), pp.17-39.

[2] Varma, P.K., 2007. The great Indian middle class. Penguin Books India.

[3] D'Mello, P., 1997. Forcing kids to be counterproductive. The Tribune, 17.

[4] Watson, D. and Tellegen, A., 1985. Toward a consensual structure of mood. Psychological bulletin, 98(2), p.219.

[5] Wikipedia.com 